\title{
Radiofrequency Ablation Therapy for Varicose Veins Guided By Ultrasound: Overview and Preliminary Experience
}

\author{
Mauricio Alvarez Tenjo $^{1}$, Oscar Javier Rincon Cardenas ${ }^{1}$ and \\ William Andres Prada Mancilla2* \\ 1Interventionist Radiologist, Hospital de la Samaritana, Colombia \\ ${ }^{2}$ Resident of Radiology and Diagnostic images, Sabana University, Colombia \\ ${ }^{3}$ Professor at Rosario University, Colombia
}

Review Article

Volume 3 Issue 3

Received Date: July 30, 2019

Published Date: August 19, 2019

DOI: $10.23880 /$ crij-16000151

*Corresponding author: William Andres Prada Mancilla, Medical Specialist in Epidemiology, Specialist in University Teaching, Master in Epidemiology, Resident of Radiology and Diagnostic images, Sabana University, Professor at Rosario University, Areandina University, Street 167 54d 48 Tower5 Apartment 402, Bogota, Colombia, Tel: (+57) 300 8719482; Email: wpradamancilla@gmail.com

\section{Abstract}

Chronic venous insufficiency manifested as varicose veins in the lower limbs results from hypertension of the superficial venous system, caused by incompetent valves in the saphenous veins. The treatment consists in the elimination of these diseased superficial veins. Classically, the treatment is performed by ligature of the saphenous-femoral junction (SFJ) and "stripping" of the abnormal saphenous vein segments, being a major surgical procedure, with a very painful postoperative period, little tolerated by patients, with poor aesthetic results and high frequency of recurrence. The technological development has led to the appearance of new minimally invasive treatments such as intravenous thermal radiofrequency ablation and laser. Radiofrequency intravenous ablation (RFA) is a relatively new, safe, effective and efficient technique that can be easily performed by interventional radiologists. A catheter is used that has an electrode that releases high frequency radiofrequency energy, producing non-thrombotic venous occlusion. The postoperative period is very well tolerated by patients and the complications are minimal. The aim of this manuscript is to present the current state of the art and our experience in the use of RFA for the treatment of venous insufficiency.

Keywords: Catheter Ablation; Ultrasound; Venous Insufficiency; Varicose Ulcers

Abbreviations: SFJ: Saphenous Femoral Junction; RFA: Radiofrequency Intravenous Ablation.

\section{Introduction}

Varicose veins in the lower limbs are the most common vascular disease in humans, affecting $20-25 \%$ of women and $10-15 \%$ of men [1]. These are caused by venous hypertension that is frequently produced by incompetent valves in the saphenous veins that condition the appearance of reverse flow in these superficial veins. This is why the treatment is aimed at eliminating the reverse flow in these veins [2]. In Colombia, the less invasive therapeutic tools that can be offered to patients 


\section{Clinical Radiology \& Imaging Journal}

with this disease are not well standardized. This article aims to describe the endovascular treatment by radiofrequency guided by ultrasound and to discuss the experience of the authors in the use of this therapeutic technique. A systematic search was carried out with the following terms MeSH and Boolean operators ( $($ "Catheter Ablation" [Majr]) AND "Venous Insufficiency" [Mesh]) OR "Varicose Ulcer" [Mesh], selecting the items with the greatest rigor in the scale epidemiological. The information and images of patients were evaluated and accepted in the scientific technical committee with the consent of the patients.

\section{Ecographic Anatomy}

The venous drainage of the lower extremities is divided into three systems:

a. The superficial venous system: It is located in the superficial compartment above the muscular fascia and drains the cutaneous microcirculation.

b. The deep venous system: It runs inside the muscular fascia and is responsible for draining the muscles of the lower extremities.

c. The perforating veins that penetrate the muscular fascia and connect the superficial and deep veins.

The superficial compartment is composed of subcutaneous tissue that contains the greater saphenous vein and its tributaries. The saphenous fascia is the portion of the membranous layer of the subcutaneous cellular tissue that is found on the saphenous veins and is thinner than the muscular fascia. All the fascias are visualizable by ultrasound and their appearance is eminently hyperechogenic. The two fascial layers form a closed space called saphenous compartment which contains the saphenous veins accompanied by arteries and nerves $[3,4]$. This compartment is easily identified in ultrasound and colloquially it has been called "Egyptian Eye" or "Ultrasonic sign of the eye".

The deep compartment corresponds to the venous structures that are inside the fascia and the ventral side of the muscles in both the thigh and the leg formed by the large veins that are accompanied by the main arteries of the lower limbs and called venous lakes in the depth of the calf muscles.

\section{Superficial Venous System}

The superficial venous system includes the reticular veins and the major and minor saphenous veins, as well as its main tributaries. The reticular system is a network of veins parallel to the surface of the skin that are located between the saphenous vein and the dermis, draining the skin of the lower extremity and the subcutaneous cellular tissue [5]. Direct communication between incompetent reticular veins and veins of the deep system through perforators has been reported in $60 \%$ of patients with extensive telangiectasias of the thigh [5].

The greater saphenous vein arises from the medial aspect of the dorsal venous arch of the foot and ascends anterior to the medial malleolus advancing on the inner side of the leg and thigh until perforating the deep fascia and joining the common femoral vein 3 or $4 \mathrm{~cm}$ below the inguinal ligament [3]. The greater saphenous vein has a terminal valve 1 to $2 \mathrm{~cm}$ distal to the saphenofemoral junction in 94 to $100 \%$ of cases. The saphenous nerve is anterior to the greater saphenous vein in the calf and may be injured in procedures that extend to this region.

As an anatomical variant of importance, the duplication of the greater saphenous vein should be mentioned, in which the division of the vein can be seen in two channels, both within the fascial compartment, reanastomosed more distally. It occurs in the thigh in $8 \%$ of cases and in the leg in up to $25 \%$ of cases [6]. The accessory and tributary branches of the greater saphenous vein are important in the pathophysiology of chronic venous disease. Usually they are two main ones in the calf: an anterior branch (anterior arch of the leg) and a posterior one (Leonardo's vein - posterior arch of the leg). In the thigh it is the accessory anterior and posterior veins that ascend parallel to the Saphenous Vein Major outside the saphenous fascia $[7,8]$.

The small saphenous vein originates from the dorsal arch of the foot, ascends posterolaterally behind the external malleolus in a variable termination in the popliteal vein. It usually has 7 to 10 closely spaced valves. The sural nerve ascends immediately lateral to the vein and usually passes below the muscular fascia before its termination [3,6-9]. The termination of the minor saphenous vein can often vary, extending to different heights of the thigh. Similarly, a cranial extension of the lesser saphenous vein that has been called the Giacomini vein or intersaphene vein is seen with some regularity and is ascertained by the appearance posteromedial of the thigh paying tribute to the greater saphenous vein (Scheme). 


\section{Clinical Radiology \& Imaging Journal}

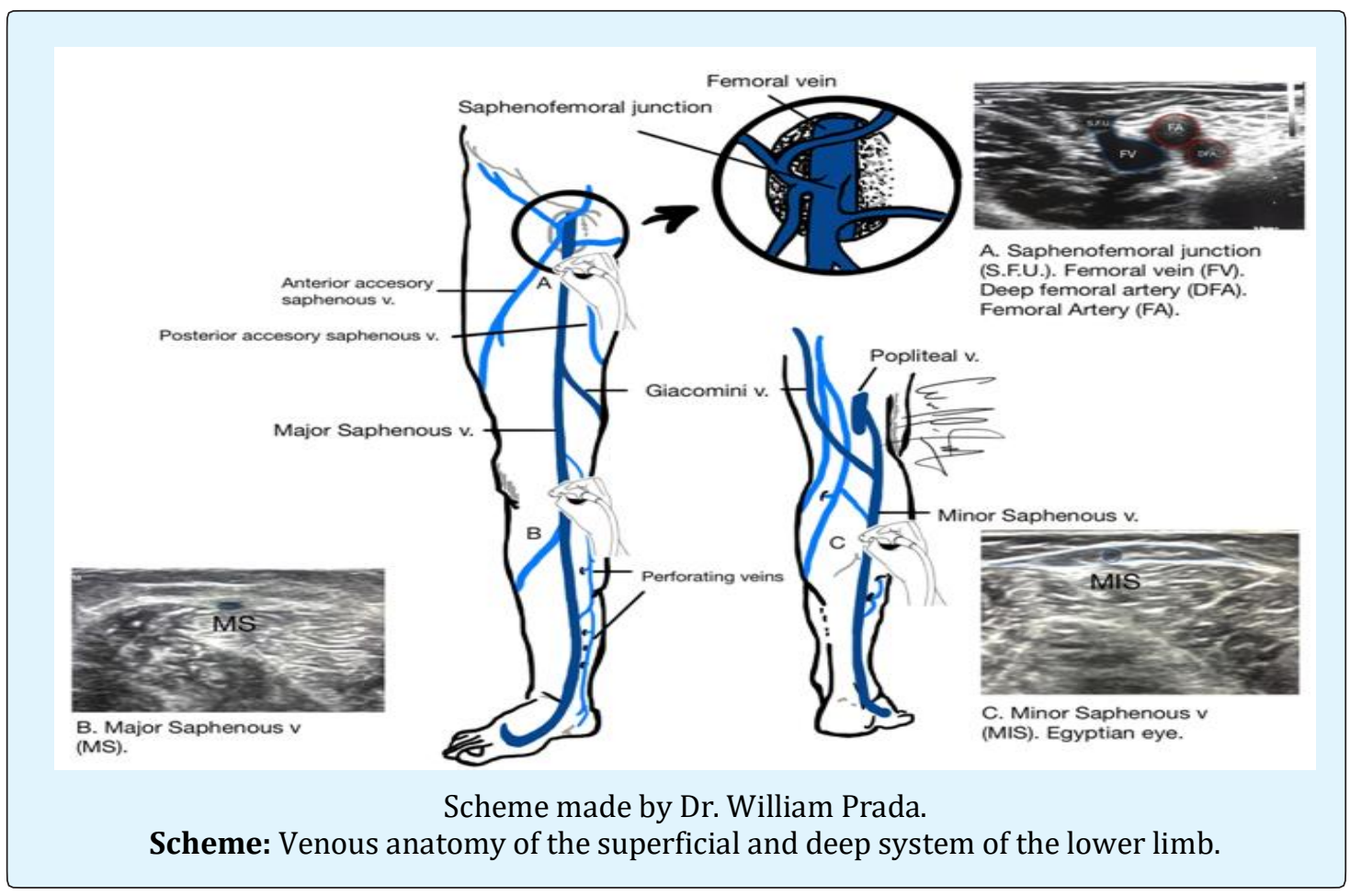

\section{Radio Frequency Equipment}

It requires radiofrequency generator equipment (high frequency equipment, bipolar to supply radiofrequency energy in a controlled manner and a bipolar catheter.) Our experience is based on the use of the CLOSURE FAST ${ }^{\mathrm{TM}}$ catheter (Covidien, Mansfield, Massachusetts, USA) This catheter has a distal therapeutic segment of $7 \mathrm{~cm}$ (for use in the Great Saphenous Vein) and $3 \mathrm{~cm}$ (for use in the Small Saphenous Vein) that has a thermo dome that takes the temperature inside the vessel, assuring the maintenance of the same between 95 and 120 degrees Celsius, using the minimum necessary power (between 15 and $40 \mathrm{~W}$ ). By means of a feedback system that connects the catheter temperature sensor with the power generating equipment [10].

\section{Mechanism of Action}

The radiofrequency is a type of electromagnetic energy, (non ionizing), is composed of electric and magnetic waves that when they come into contact with the tissue cause vibration and friction of their atoms producing thermal energy (resistive or ohmic heat). The increase in temperature generated by the RF (between 95 and $120^{\circ} \mathrm{C}$ ) causes a series of changes in the vein structure treated between those that are the endothelial destruction, denaturation and contraction of the collagen fibers, thickening of the venous wall with reduction of the light of the glass. Thus, the therapeutic objective is to induce fibrotic occlusion of the treated vein and its subsequent disappearance due to atrophy. (Fibrotic vein occlusion - non-thrombotic) [11,12]. It is important to avoid very high temperatures, which could cause boiling, vaporization and carbonization of the tissues, as happens with the endolaser, which generates temperature peaks between 700 and 1500 oC [11,12]. Today it is accepted that surgical dissection in the groin, performed in the conventional procedure, is a stimulus for neovascularization. In RFA by avoiding such dissection, there is no stimulus for revascularization, potentially reducing the recurrence of varicose veins [2].

\section{Technical Aspects}

This is a procedure completely guided by color Doppler ultrasound, does not require sedation and can be performed in an ambulatory environment. Access to the greater saphenous vein is performed with puncture below the knee using Seldinger's percutaneous technique with a micro-puncture device (Figure 1). A short vascular introducer (No. 7Fr) is then placed through which the catheter is advanced by sonographic guidance proximally and is located $2 \mathrm{~cm}$ below the sapheno-femoral junction (Figure 2) [13]. 


\section{Clinical Radiology \& Imaging Journal}

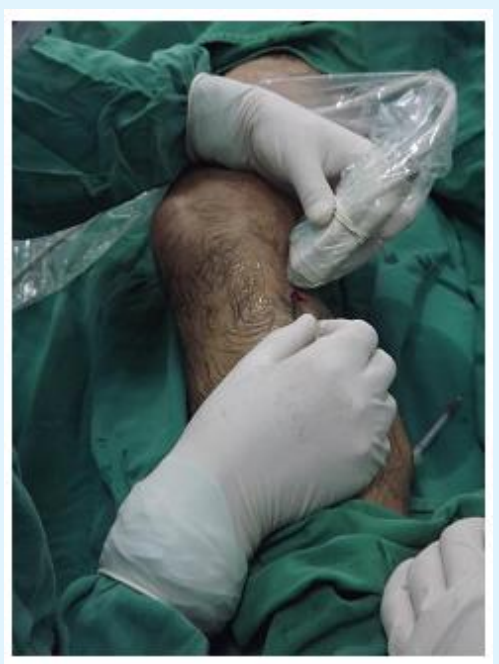

Figure 1: Initial puncture of the greater saphenous vein with ultrasound guidance.

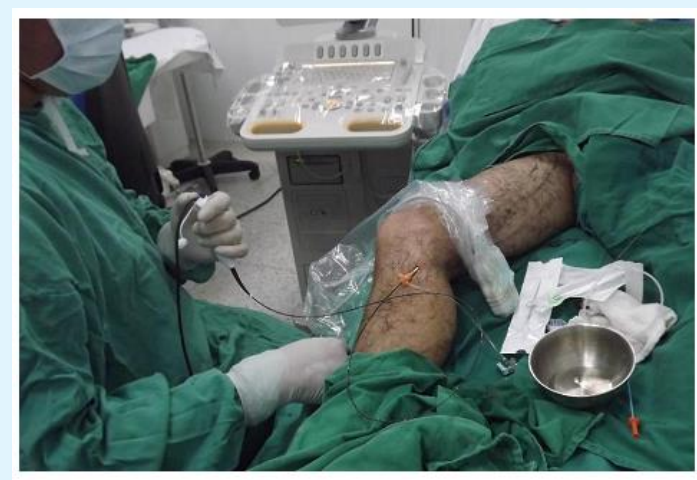

Figure 2: Vascular introducer $7 \mathrm{~F}$ in the greater saphenous vein and radiofrequency catheter ready to advance.

Tumescent local anesthesia (ultrasound-guided injection of "Klein's solution": mixture of lidocaine, adrenaline, bicarbonate and physiological saline), which is injected into the saphenous compartment, is used to analgesize, protect the skin and neighboring tissues against heat, and promote venous collapse [1]. Both lower limbs can be treated in the same "surgical act" and the recovery time is short. To obtain successful results requires a complete understanding of the disease, an exquisite handling of the technique of color Doppler ultrasound and also a good knowledge of the anatomy of the superficial venous system. Treatment for RFA has been successfully performed in the greater saphenous vein, the small saphenous vein and the Giacomini vein, and recently in incompetent perforators $[13,14]$.

\section{Postprocediment Management}

a. Ambulation starts immediately and must be done for the rest of the day.

b. Large periods of immobilization should be avoided after the radiofrequency procedure to minimize the risk of venous stasis that could increase the risk of thrombus formation.

c. Control with color Doppler ultrasound at three days, a week and a month after the procedure.

\section{Efficacy of Radio Frequency}

As of 1990 there are scientific works that demonstrate that the RFA is a safe and effective method to abolish the reflux of the saphenous vein [15], as described by Merchant RF, et al. in which complete improvement of saphenous vein insufficiency is reported greater with RFA (between 90 and 100\%) of the cases, making follow-ups between three months and four years [14,16]. RFA equals conventional surgery in efficacy but it is also clearly superior in terms of less postoperative pain, better quality of life and faster recovery $[17,18]$. Likewise, it is a safe and effective procedure for the treatment of varicose veins; it is associated with high rates of success and satisfaction on the part of patients $[19,20]$. A systematic review published in 2018 by Poder TG, et al. reports that although the level of evidence currently regarding the effectiveness of RFA is with observational studies, the efficacy is comparable to open surgery and laser therapy, exposing lower degree of complications and shorter hospital stay [15].

Compared with laser ablation, the results show that despite having good long-term results, it presents a higher risk of skin burns because the temperatures reached by the probe during treatment are much higher than those achieved with radiofrequency, generating even more postoperative pain. On the other hand, sub-treated venous segments can be found that recanalize in a short time and frequent lesions of nerves adjacent to the veins that condition paresthesias, dysesthesias and anesthesia [21]. There is less data regarding the minor saphenous vein but the results are quantitatively similar [8].

\section{Complications}

The majority of adverse events generated after the radiofrequency procedure are minor. Among which are the following:

a. Ecchymosis. They are usually frequent and take 7 to 14 days to disappear. 


\section{Clinical Radiology \& Imaging Journal}

b. After the procedure and for about 3 weeks there is thickening sensation along the vein treated, this is due to the inflammation process and spontaneously improves with the administration of non-steroidal antiinflammatory and medium compression stockings.

c. Surface phlebitis of varicose tributaries. It is another rare collateral effect and is reported in 5\% of cases [16]. Its management is conservative with non-steroidal antiinflammatories and medium compression stockings, as well as ambulation.

d. Burn: Complication derived from any type of thermal ablation. It is avoided by performing adequate tumescent anesthesia isolating the vein to be treated for fascia, muscle planes and subcutaneous cellular tissue.

Others: Paresthesia in 3.2\% and Skin pigmentation in 2\%.

e. When veins recanalize after RFA, this happens in the first 12 months and it is suggested that recanalization may be related to insufficient energy release during treatment [22].

\section{Our Experience}

From March 2013 to February 2019, we performed in 120 patients, 250 procedures (114 larger saphenous veins without ulcer, 9 greater saphenous veins with ulcer, and 29 minor saphenous veins without ulcer with satisfactory results) (Figures $3 \& 4$ ). The procedure has improved with the experience over the years, from 4 hours of the first procedures to about one hour today. The remission of the disease in our experience is very high and the complication rate is very low, from the post operative pain that improves with oral analgesia, even small bruises in the first days that resolve completely a week. In the experience with patients with profound venous system insufficiency, the results are less effective, due to the persistent reverse flow from the deep to the superficial system. In general, the effectiveness of the treatment is really high and the physiological and cosmetic results are very good (Figure 5).

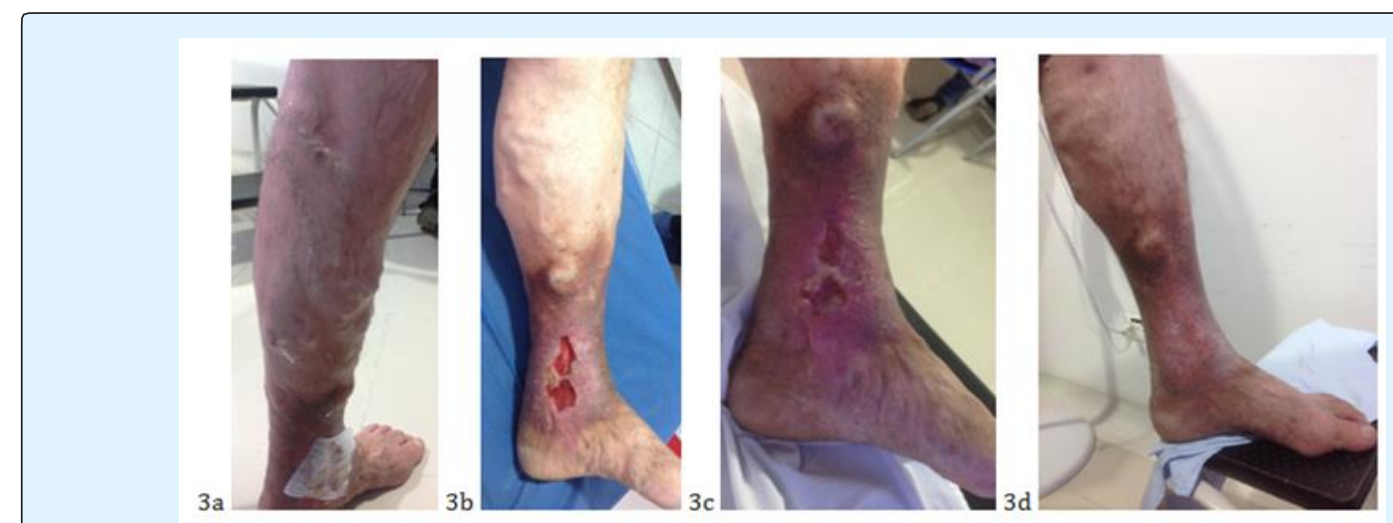

3a: First evaluation, 3b: Immediate pretoperative, 3c: Postoperative day 7, 3d: Postoperative day 60.

Figure 3: Results of radiofrequency treatment.

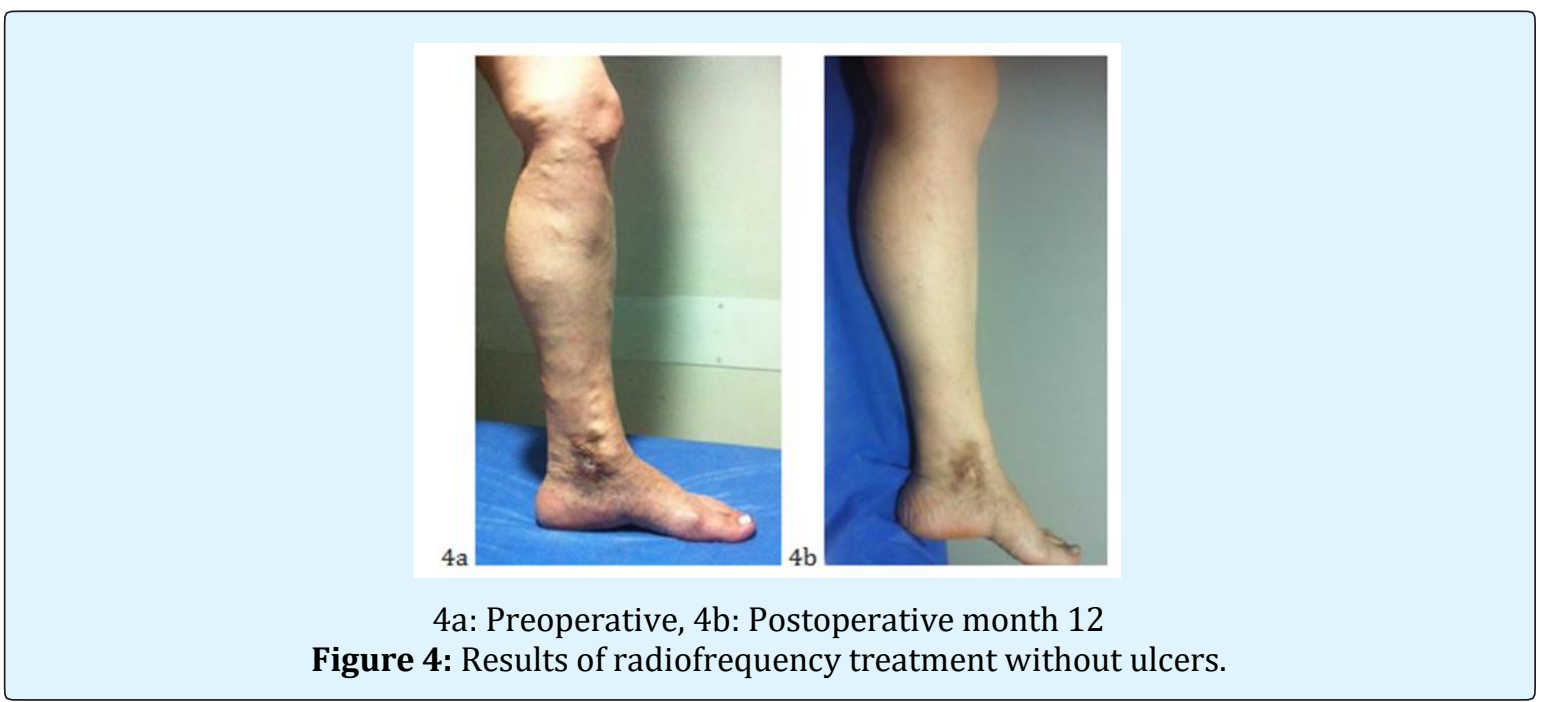

William Andres PM, et al. Radiofrequency Ablation Therapy for 


\section{Clinical Radiology \& Imaging Journal}

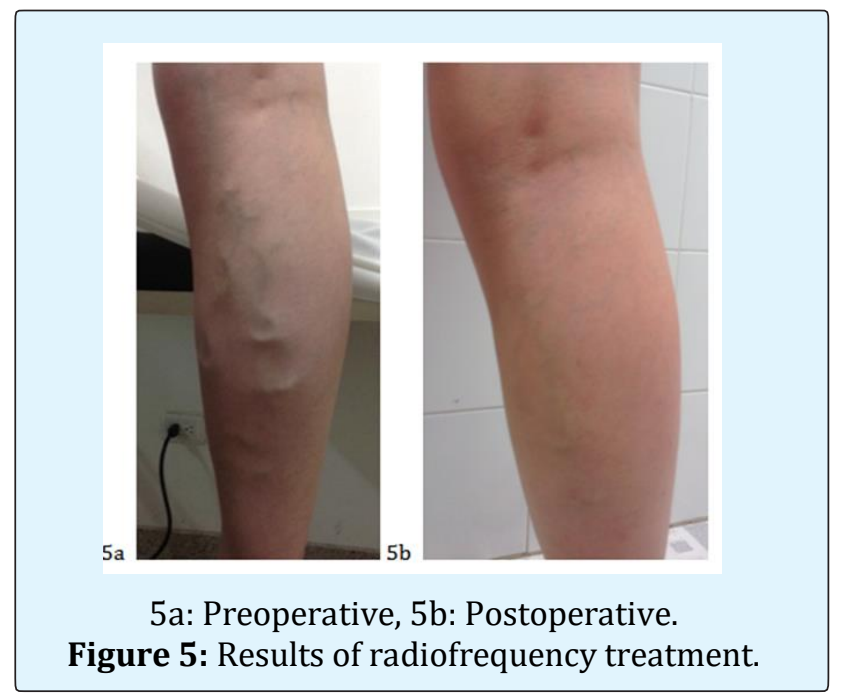

\section{Conclusion}

The introduction of minimally invasive intravenous procedures in the last decade has stimulated interest in venous diseases. Today RFA is a highly safe and effective technique for the management of varicose veins since it is associated with a high rate of success and a high degree of satisfaction on the part of patients [23]. It has demonstrated its superiority over conventional surgery with a higher level of scientific evidence [17]. Additionally, it is less painful and offers a better quality of life than the endolaser [10]. In our country, it is still a therapeutic alternative with little use. But nevertheless; our experience shows excellent results with a very low rate of complications that can contribute to the change in the therapeutic approach of patients with venous insufficiency.

\section{References}

1. García-Madrid C, Pastor Manrique JO, Gómez Blasco F, Sala Planell E (2011) New advances in the treatment of varicose veins: endovenous radiofrequency VNUS Closure®. Cir Esp 89(7): 420-426.

2. Subramonia S, Lees TA (2007) The treatment of varicose veins. Ann R Coll Surg Engl 89(2): 96-100.

3. Caggiati A (1999) The saphenous venous compartments. Surg Radiol Anat 21(1): 29-34.

4. Oğuzkurt L (2012) Ultrasonographic anatomy of the lower extremity superficial veins. Diagn Interv Radiol 18(4): 423-430.
5. Somjen GM (1995) Anatomy of the superficial venous system. Dermatol Surg 21(1): 35-45.

6. Mozes G, Gloviczki P, Menawat SS, Fisher DR, Carmichael SW, et al. (1996) Surgical anatomy for endoscopic subfascial division of perforating veins. J Vasc Surg 24(5): 800-808.

7. Caggiati A, Bergan JJ (2002) The saphenous vein: derivation of its name and its relevant anatomy. J Vasc Surg 35(1): 172-175.

8. Caggiati A, Bergan JJ, Gloviczki P, Eklof B, Allegra C, et al. (2005) Nomenclature of the veins of the lower limb: extensions, refinements, and clinical application. J Vasc Surg 41(4): 719-724.

9. Caggiati A, Bergan JJ, Gloviczki P, Jantet G, WendellSmith CP, et al. (2002) Nomenclature of the veins of the lower limbs: an international interdisciplinary consensus statement. J Vasc Surg 36(2): 416-422.

10. Winterborn RJ, Corbett CR (2008) Treatment of varicose veins: the present and the future--a questionnaire survey. Ann R Coll Surg Engl 90(7): 561-564.

11. Schmedt CG, Sroka R, Steckmeier S, Meissner OA, Babaryka G, et al. (2006) Investigation on radiofrequency and laser $(980 \mathrm{~nm})$ effects after endoluminal treatment of saphenous vein insufficiency in an ex-vivo model. Eur J Vasc Endovasc Surg 32(3): 318-325. 


\section{Clinical Radiology \& Imaging Journal}

12. Schmedt CG, Meissner OA, Hunger K, Babaryka G, Ruppert V, et al. (2007) Evaluation of endovenous radiofrequency ablation and laser therapy with endoluminal optical coherence tomography in an ex vivo model. J Vasc Surg 45(5): 1047-1058.

13. Proebstle TM, Alm J, Göckeritz O, Wenzel C, Noppeney T, et al. (2011) Three-year European follow-up of endovenous radiofrequency-powered segmental thermal ablation of the great saphenous vein with or without treatment of calf varicosities. J Vasc Surg 54(1): 146-152.

14. Merchant RF, DePalma RG, Kabnick LS (2002) Endovascular obliteration of saphenous reflux: a multicenter study. J Vasc Surg 35(6): 1190-1196.

15. Poder TG, Fisette JF, Bédard SK, Despatis MA (2018) Is radiofrequency ablation of varicose veins a valuable option? A systematic review of the literature with a cost analysis. Can J Surg 61(2): 128-138.

16. Chwała M, Szczeklik W, Szczeklik M, AleksiejewKleszczyński T, Jagielska-Chwała M (2015) Varicose veins of lower extremities, hemodynamics and treatment methods. Adv Clin Exp Med 24(1): 5-14.

17. Rautio T, Ohinmaa A, Perälä J, Ohtonen P, Heikkinen $\mathrm{T}$, et al. (2002) Endovenous obliteration versus conventional stripping operation in the treatment of primary varicose veins: a randomized controlled trial with comparison of the costs. J Vasc Surg 35(5): 958965.

18. Lurie F, Creton D, Eklof B, Kabnick LS, Kistner RL, et al. (2005) Prospective randomised study of endovenous radiofrequency obliteration (closure) versus ligation and vein stripping (EVOLVeS): twoyear follow-up. Eur J Vasc Endovasc Surg 29(1): 6773.

19. Goode SD, Chowdhury A, Crockett M, Beech A, Simpson R, et al. (2010) Laser and radiofrequency ablation study (LARA study): a randomised study comparing radiofrequency ablation and endovenous laser ablation $(810 \mathrm{~nm})$. Eur J Vasc Endovasc Surg 40(2): 246-253.

20. Almeida JI, Kaufman J, Göckeritz O, Chopra P, Evans MT, et al. (2009) Radiofrequency endovenous ClosureFAST versus laser ablation for the treatment of great saphenous reflux: a multicenter, singleblinded, randomized study (RECOVERY study). J Vasc Interv Radiol 20(6): 752-759.

21. Rasmussen LH, Lawaetz M, Bjoern L, Vennits B, Blemings A, et al. (2011) Randomized clinical trial comparing endovenous laser ablation, radiofrequency ablation, foam sclerotherapy and surgical stripping for great saphenous varicose veins. Br J Surg 98(8): 1079-1087.

22. Siribumrungwong B, Noorit $P$, Wilasrusmee $C$, Attia J, Thakkinstian A (2012) A systematic review and metaanalysis of randomised controlled trials comparing endovenous ablation and surgical intervention in patients with varicose vein. Eur J Vasc Endovasc Surg 44(2): 214-223.

23. Kayssi A, Pope M, Vucemilo I, Werneck C (2015) Endovenous radiofrequency ablation for the treatment of varicose veins. Can J Surg 58(2): 85-86. 